\title{
Pyrroloquinoline quinone glucose dehydrogenase adopted in thermometric analysis for enhancement of glucose determination
}

\author{
Weihong Xie ${ }^{1,2} \cdot$ Leif Bülow ${ }^{1} \cdot$ Bin Xie $^{1}$ (D)
}

Received: 3 October 2017 / Accepted: 4 April 2018 / Published online: 26 April 2018

(C) The Author(s) 2018, corrected publication May 2018

\begin{abstract}
A broad measurement range of glucose is often required in clinical analysis, especially for diabetic patients where glucose levels can be very high. Pyrroloquinoline quinone glucose dehydrogenase (PQQGDH) has previously been used in electrochemical quantification of glucose with an extended linear range. However, in real sample determination of glucose, interferences from electroactive substances in blood are unavoidable. Calorimetric biosensors, e.g., the Enzyme Thermistor, are insensitive to either directly electroactive or optical interferences often present in real clinical samples. This paper describes a novel analytical strategy where the intrinsic advantages of PQQGDH are combined with the Enzyme Thermistor as biosensor using calorimetric detection as general measurement principle. When compared with the most frequently used enzyme glucose oxidase, PQQGDH has a higher catalytic efficiency and is insensitive to the availability of oxygen. The use of calorimetry in this context resulted in a broad linear range of glucose measurements, from 0.009 to $100 \mathrm{mM}$, an excellent specificity and insignificant side effects of compounds present in blood at high concentrations, such as lactate and urea.
\end{abstract}

Keywords Pyrroloquinoline quinone glucose dehydrogenase · Enzyme Thermistor (ET) · Thermal biosensor . Glucose $\cdot$ Clinical analysis

\section{Introduction}

Bioanalytical calorimetry measures the enthalpy change of a reaction. As biological reactions often are exothermic, calorimetry provides a useful tool to track a biological process by measuring the heat produced [1]. In early studies, calorimeters were designed in a sophisticated and expensive fashion, implying that their use in basic research and applied analyses was limited. In the 1970s, Danielsson

The original version of this article was revised due to a retrospective Open Access with the fee covered under the Swedish Compact agreement.

Bin Xie

bin.xie@tbiokem.lth.se

1 Pure and Applied Biochemistry, Department of Chemistry, Lund University, Naturvetarvägen 14, Box 124, 22100 Lund, Sweden

2 Present Address: Department of Food and Pharmaceutical Engineering (Ministry of Education), Hubei University of Technology, Wuhan 430068, China and Mosbach developed a new type of calorimeter which was called the Enzyme Thermistor (ET) [2,3]. The device was small and simple, but still very efficient in monitoring an enzymatic reaction. Consequently, it attracted immediate attention in the biosensor area at its very first emergence. Over the years, several successful studies have been completed with the ET and results have been presented using a variety of enzymes. Applications have been demonstrated in a range of fields, including clinical analysis [4-7], process control [8-10], environmental control [11-13], fermentation monitoring [14, 15], and food safety analysis [16-18]. Particularly glucose quantification based on glucose oxidase (GOD) $[4,5,7]$ in different samples has been studied extensively using this device.

Besides identifying suitable enzymes for calorimetric measurements, the ET has been developed as an instrument in itself. Particularly, miniaturization has proved valuable, resulting in a miniaturized version of the ET, and a thermal microchip and integrated silicon thermopiles have been devised. These achievements have opened for designing new cost-effective calorimetric micro-biosensors [19-22]. Since a small device utilizes minimal amounts of enzyme, 
the obtained sensor signal will decrease. An attractive option to solve this issue is to use enzymes with high intrinsic catalytic power.

Soluble glucose dehydrogenase (s-GDH; EC 1.1.99.17), also named pyrroloquinoline quinone glucose dehydrogenase (PQQGDH-B) from Acinetobacter calcoaceticus, is a classical quinoprotein which requires the cofactor pyrroloquinoline quinone (PQQ) in its reaction with glucose [23]. The enzyme oxidizes glucose to gluconolactone with the concomitant reduction of PQQ to $\mathrm{PQQH}_{2}$. A subsequent electron acceptor is required to transfer the electrons from the reduced cofactor to regenerate the enzyme. Although the actual physiological electron acceptor for this enzyme is unknown, a number of artificial electron acceptors, such as phenazine methosulfate (PMS) [24], have been found effective. To date, only the first part of the catalytic cycle, i.e., the reductive half-reaction, has been investigated [24] and only limited knowledge has been gained about the later redox step.

Different glucose sensors based on PQQGDH-B have been described. Most of these devices have used electrodes as transducers that measure the current generated during the enzymatic reaction [25-27]. In electrochemical measurements, an electrode mediator or a modified electrode surface is generally required. A variety of electron mediators and electron conductive polymers have been employed [28-32], among which PMS has been found to be the most efficient [26]. Despite the popularity of electrochemical sensors, different shortcomings of these devices are still persistent, like leakage of the enzyme from immobilized layers or denaturation of the enzyme on the electrode surface. These obstacles may largely affect the lifetime and operational stability of the enzyme-modified electrodes. The measurement range of these methods for glucose is not wide, normally up to $20 \mathrm{mM}$. In samples where electroactive impurities are present, interferences are difficult to avoid. Even though a PQQ-dependent dehydrogenase-based optical glucose sensor also has been developed [33], it also encounters problems when a colored impurity is present. Therefore, development of a PQQGDH biosensor based on detection mechanisms other than the electrochemical and optical principles is necessary, in order to fully explore the properties of PQQGDH for glucose determinations.

In this paper, a calorimetric biosensor based on the ET principle using PQQGDH for glucose detection has been examined. The sensitivity, linear range, oxygen and electron acceptor effects, as well as interferences from other cosubstrates have been investigated.

\section{Materials and methods}

\section{Chemicals and materials}

Spherical controlled pore glass (CPG) beads with particle size of $100-160 \mu \mathrm{m}$ and a mean pore diameter of $50 \mathrm{~nm}$ were purchased from VEB Trisola, Steinach, Germany. Apo-glucose dehydrogenase (EC 1.1.99.17; Apo-sGHD) was obtained from University of Potsdam (Germany). Pyrroloquinoline quinone (PQQ), phenazine methosulfate (PMS), Tris free acid, glutaraldehyde, D-(+)-glucose, urea, and lactate were purchased from Sigma-Aldrich. $\mathrm{KCl}$ and $\mathrm{CaCl}_{2}$ were from Merck. HEPES buffer of $20 \mathrm{mM}$ containing $20 \mathrm{mM} \mathrm{KCl}$ and $1 \mathrm{mM} \mathrm{CaCl}{ }_{2}$ was prepared using deionized (18 M $\Omega$ ) water from Milli-Q system (Millipore, Bedford, MA, USA), and $\mathrm{pH}$ was adjusted to 7.5 with $\mathrm{KOH}$. Glucose solutions of different concentrations were prepared by dilutions from a $1 \mathrm{M}$ stock solution.

\section{Preparation of the enzyme column}

$2 \mathrm{~mL}$ of $2.5 \%$ glutaraldehyde was added to $500 \mathrm{mg}$ controlled porous glass (CPG) and mixed under aspiration for $30 \mathrm{~min}$. The pressure was then reduced for another $30 \mathrm{~min}$. The beads were subsequently extensively washed with 300-400 mL Milli-Q water. The activated glass beads were kept in water at $4{ }^{\circ} \mathrm{C}$ before use. For enzyme immobilization, the activated CPG was mixed with PQQGDH at a ratio of $0.5 \mathrm{mg}$ (400 units) of enzyme to $75-\mathrm{mg}$ glass beads. The coupling reaction was allowed to proceed overnight at $4{ }^{\circ} \mathrm{C}$ with mild agitation. The enzyme-carrying beads were finally washed with the HEPES buffer. In our experiments, $35-\mathrm{mg}$ beads were loaded in one enzyme column.

\section{Instrumentation and assay conditions}

The measurements were performed with the ET biosensor as described by Danielsson [34]. The instrument was constructed by Lund University (Sweden) and coupled with flow injection analysis. The enthalpy change from the enzyme catalysis correspondingly caused a temperature increase that was registered by the ET. The thermometric probe was designed as a polyacrylate tube which could fit to the immobilized enzyme column at one end. The outlet of the probe contained gold tubing onto which a sensitive thermistor was attached. Two parallel flow streams were generated in two separate flow channels thermostatted at $25{ }^{\circ} \mathrm{C}$, one as the measurement probe vs another reference probe for differential detection of the enzyme reaction. The running buffer was pumped through the Enzyme Thermistor unit with a peristaltic pump at a flow rate $0.8 \mathrm{~mL} /$ 
min, while the samples were introduced via a sample valve with a $0.1-\mathrm{mL}$ sample volume. For anaerobic detection, the buffer and the sample solution were thoroughly deoxygenated with $\mathrm{N}_{2}$ before measurement.

\section{Results and discussion}

\section{Calorimetric analysis of glucose catalyzed by PQQGDH}

Soluble glucose dehydrogenase (s-GDH) is a classical quinoprotein which requires the cofactor pyrroloquinoline quinone (PQQ) to oxidize glucose to gluconolactone. The reaction mechanism of PQQ-dependent enzymes has remained elusive due to the absence of comprehensive structural data [35]. However, Dokter et al. [36] have found that reduced PQQ $\left(\mathrm{PQQH}_{2}\right)$ can transfer electrons to cytochrome $b_{562}$. A number of artificial electron mediators, such as phenazine methosulfate (PMS), 2,6-dichlorophenolindophenol (DCIP), Wurster's Blue, ruthenium complex, and electron-conducting polymers, were also able to shuttle electrons from the reduced enzyme in electrochemical studies [24]. The reaction catalyzed by PQQGDH can thus be driven by these electron acceptors. The possible electron transfer path during the enzymatic reaction is shown in Fig. 1.

PMS has previously been shown to be the most efficient electron acceptor [24] and was therefore chosen in this study. Glucose solutions of $0.78,1.56,3.12,6.25,12.5,25$, $50,100 \mathrm{mM}$ were prepared from a $1 \mathrm{M}$ stock and were injected into the ET system. In the absence of PMS, only small thermal response could be detected and the signal did not show proportional relationship with the glucose concentration (Fig. 2). When PMS was added into the glucose samples up to a concentration of $50 \mathrm{mM}$, the thermal response increased as compared with that obtained in the absence of the electron acceptor (Fig. 2). The linear response range could be extended over concentration of $100 \mathrm{mM}$ under the conditions used. A correlation coefficient of 0.999 was obtained.

In order to investigate whether the enhanced signal response was merely caused by the electron mediator itself, a control experiment was carried out by injecting PMS without glucose. Results showed that PMS only produced negligible signals in the absence of glucose. To examine the signal dependence only on glucose concentration, measurements at a fixed PMS concentration were performed. The glucose detection linear range was up to $25 \mathrm{mM}$ at $10 \mathrm{mM}$ PMS and extended to $50 \mathrm{mM}$ and over $100 \mathrm{mM}$ at 30 and $50 \mathrm{mM}$ PMS, respectively (Fig. 2). The linear range of glucose detection increased by increments of the electron acceptor PMS concentration, which indicates that more electron acceptors are required for detecting a higher substrate concentration.

Similarly, experiments were carried at a fixed glucose concentration to investigate the influence of different PMS concentrations on the glucose measurement. It could be
Enzyme substrate<smiles>OC1C(O)C(O)C(O)C(O)C1O</smiles>

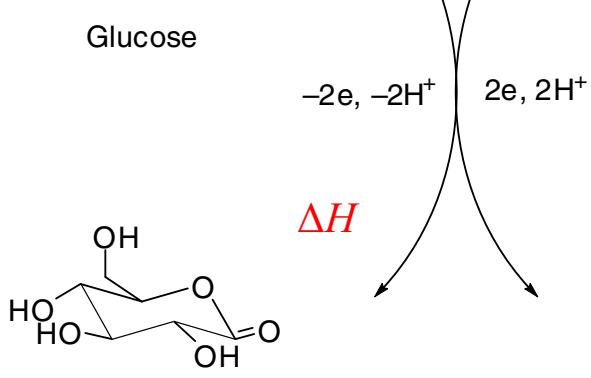

Gluconolactone
Enzyme cofactor<smiles>O=C(O)c1cc(C(=O)O)c2c(n1)C(=O)C(=O)c1cc[nH]c1-2</smiles>

$P Q Q$
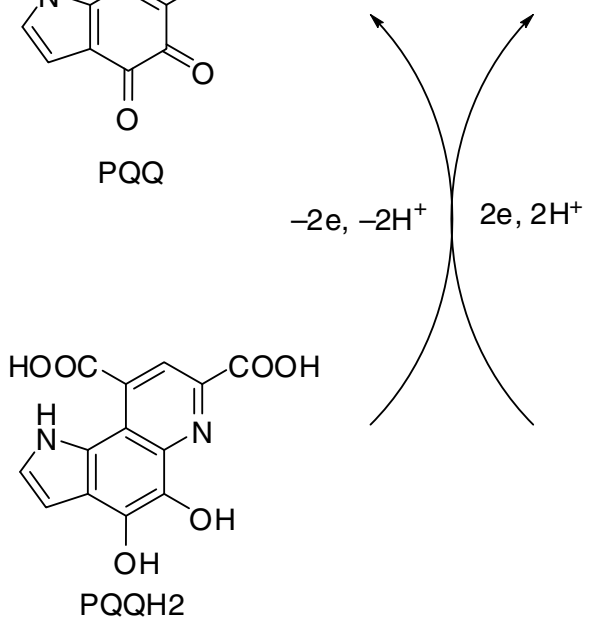

Electron acceptor<smiles>CN1c2ccccc2NC2C=CC=C[C-]21</smiles>

PMSH2<smiles>C[n+]1c2ccccc2nc2ccccc21</smiles>

PMS

Fig. 1 Principle of PQQGDH-based thermometric determination of glucose. $\Delta H$ is the enthalpy generated by PQQGDH catalyzing glucose and determined with the Enzyme Thermistor biosensor 


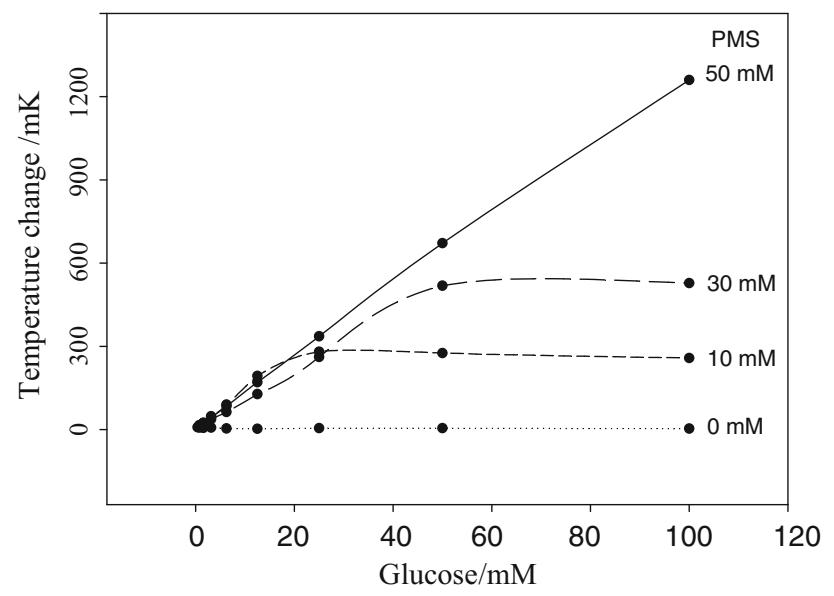

Fig. 2 The dependence of the glucose linear range on PMS concentrations

verified that more PMS was required to get a proportional response signal for higher levels of glucose (Fig. 3). It was estimated that the concentration of PMS needed should not be less than half of the glucose concentration. Above this PMS to glucose ratio, the glucose detection was not affected. The fact that less concentration of PMS than glucose was required is due to a dilution of the glucose sample during transportation from the sample valve to the enzyme column as the PMS was constant in running buffer. Similar effects have been observed in our previous glucose studies [20].

\section{The sensitivity of the PQQGDH-ET}

The above results demonstrated that PQQGDH-ET could detect glucose up to $100 \mathrm{mM}$. In order to identify the measurement resolution of glucose, experiment was performed in the same measurement conditions for different

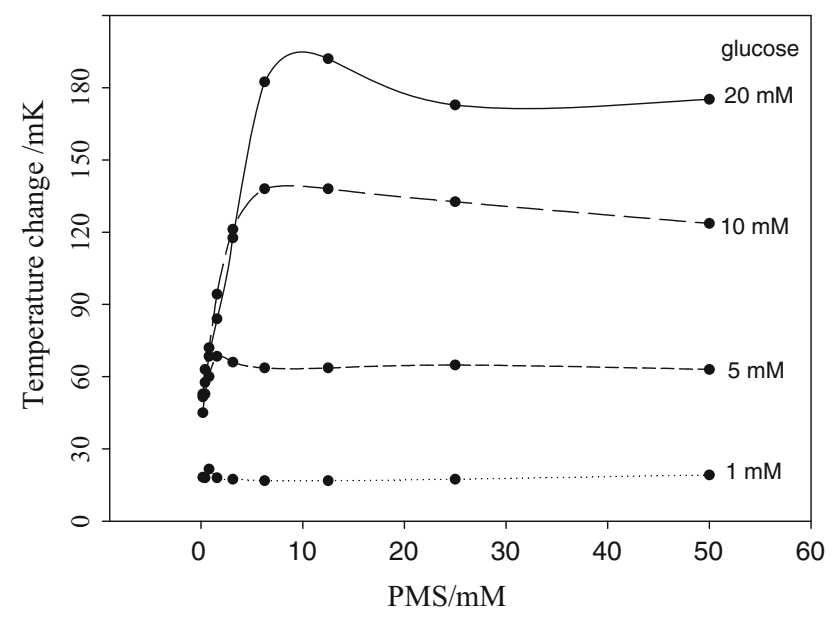

Fig. 3 The effect of different PMS concentrations on the glucose detection glucose concentrations by a twofold serial dilution from $20 \mathrm{mM}$ glucose. The result proved that the ET could generate a detection limit as low as $0.009 \mathrm{mM}$ glucose. The correlation coefficients 0.995 and 0.999 in the linearity of calibration curves were obtained for glucose measurement range from 0.009 to $20 \mathrm{mM}$ and from 0.009 to $0.62 \mathrm{mM}$, respectively. This study explained that the linear measurement range could cover from 0.009 to $100 \mathrm{mM}$ of glucose using the PQQGDH-ET. In comparison with previous GOD-based ET analysis, the measurement range of glucose is much broader using PQQGDH than GOD (normally less than $30 \mathrm{mM}$ ) [4]. The wide linear range of glucose analysis is valuable both for diabetes analysis in clinical settings and in fermentation process control.

\section{The reliability of PQQGDH-ET}

The stability of the measurement system was tested by repetitive injections of eleven $5 \mathrm{mM}$ glucose samples. The data shown in Table 1 resulted in a standard deviation of 0.21 . The lifetime of the biosensor performance was also demonstrated over 4 months by determining the ET response of different concentrations of glucose $(0.78,1.56$, $3.12 \mathrm{mM}$, respectively) shown in Fig. 4. The results indicated that the PQQGDH-ET was very stable with standard deviation of 0.25 . The stability of the measurement system was due to the optimized immobilization of the enzyme and the reliable operating conditions.

\section{Effects of $\mathrm{N}_{2}$ and $\mathrm{O}_{2}$}

One of the advantages when comparing PQQGDH with glucose oxidase in glucose determination is that PQQGDH is oxygen independent. In order to ascertain potential effects of $\mathrm{N}_{2}$ and $\mathrm{O}_{2}$, experiments were carried out using oxygen and $\mathrm{N}_{2}$-saturated buffers, respectively. The results

Table 1 The data of 11 continuous measurements obtained from the PQQGDH Enzyme Thermistor, $5 \mathrm{mM}$ glucose in HEPES buffer

\begin{tabular}{llll}
\hline Exp. number & Temperature/mK & Mean & SD \\
\hline 1 & 61.8 & & \\
2 & 61.2 & & \\
3 & 60.3 & & \\
4 & 61.8 & & \\
5 & 61.8 & 61.8 & 0.021 \\
6 & 61.5 & & \\
7 & 62.1 & & \\
8 & 62.4 & & \\
9 & 62.4 & & \\
10 & 62.4 & & \\
11 & 61.2 & & \\
\hline
\end{tabular}




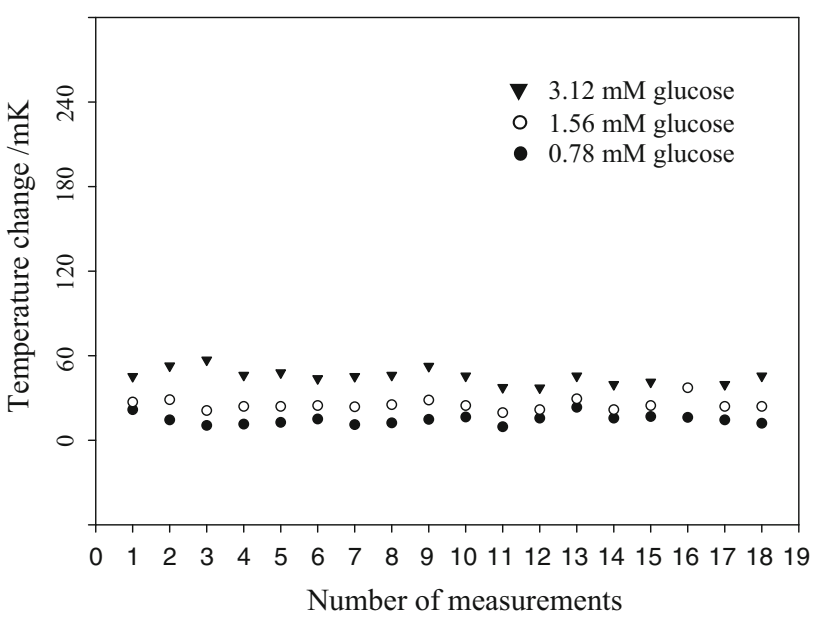

Fig. 4 The stability of the PQQGDH-ET. The data were obtained during 4 months for the repeated experiments with the same measurement system and conditions

showed insignificant difference between the two different conditions, which indicated that PQQGDH was oxygen independent in the calorimetric measurement of glucose (Fig. 5).

In the course of glucose turnover, two substrates are involved in the enzymatic reaction. The first substrate is the carbohydrate that reacts with the enzyme and performs the reductive half-reaction in which the glucose is converted to lactone and the cofactor of the enzyme is converted to its reduced form. The second substrate is an oxidizing reagent to the reduced enzyme cofactor. In the case of glucose oxidase, the enzyme cofactor is FAD. The redox potential of the $\mathrm{FAD} / \mathrm{FADH} \mathrm{H}_{2}$ couple is very low (negative) so that a wide variety of oxidizing substrates, such as molecular oxygen, quinones, and some one-electron acceptors, can react with the reduced enzyme. Therefore, the measurements based on mediator reactions with glucose oxidase

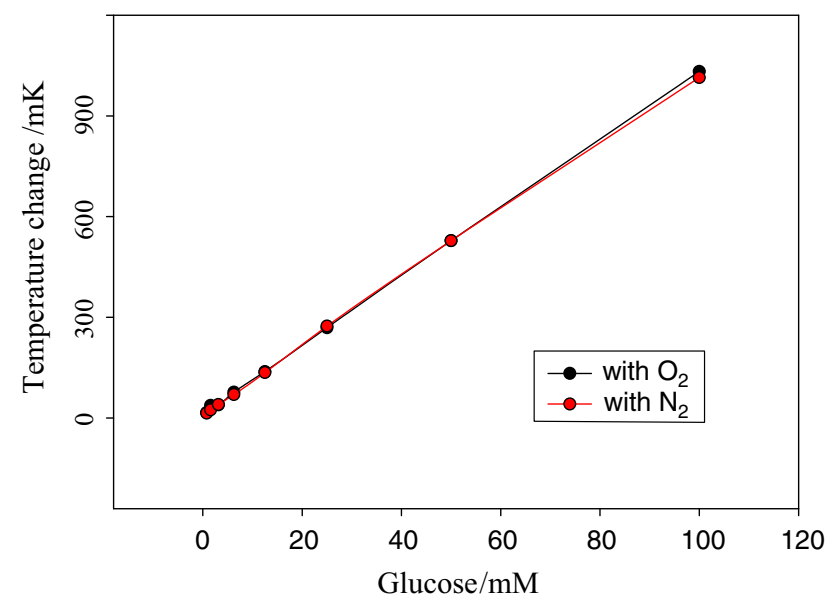

Fig. 5 Comparison of the responses obtained with PQQGDH-ET in oxygen- and nitrogen-saturated buffers, respectively are always influenced by possible oxygen interferences. In comparison, the glucose dehydrogenase binds PQQ as cofactor whose reduced form is unable to reduce molecular dioxygen, thus eliminating the interference of natural oxygen.

\section{Effects of the cofactor}

The cofactor of the enzyme, PQQ, is in itself a redox active compound, and it has been used as an electron mediator in glucose sensors [37]. Experiments with PQQ in the absence of the apo-enzyme showed that PQQ also generated a response to glucose at the same conditions, even though the signal to glucose was much smaller compared to those obtained from the holo-enzyme (Fig. 6). It indicated that PQQ was the functional moiety but which gained specificity and enhanced catalytic efficiency by the protein part.

\section{Effects of lactate and urea}

Lactate and urea are other two important metabolites in clinical diagnostics and personal health monitoring. In order to verify possible influence of the two substrates on the thermometric detections, lactate and urea in as same concentration as the glucose were injected into the PQQGDH-ET. No significant interferences from the two substances were observed in comparison with the glucose response (Fig. 7). These results verified that PQQGDH-ET could specifically determine glucose in sample mixtures containing lactate or urea, such as blood, so that this method could be applied in clinical analysis of blood.

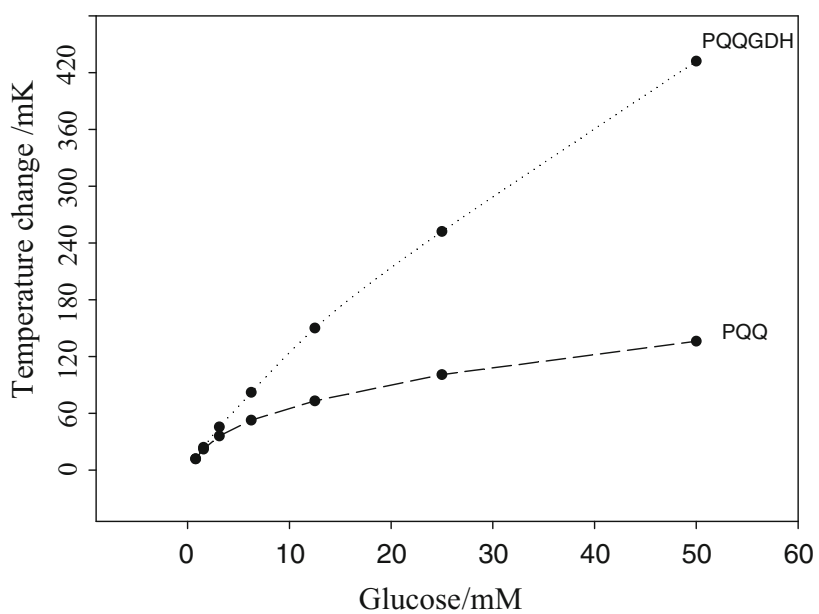

Fig. 6 Comparison of the glucose detections obtained under the condition of PQQGDH and PQQ, respectively 


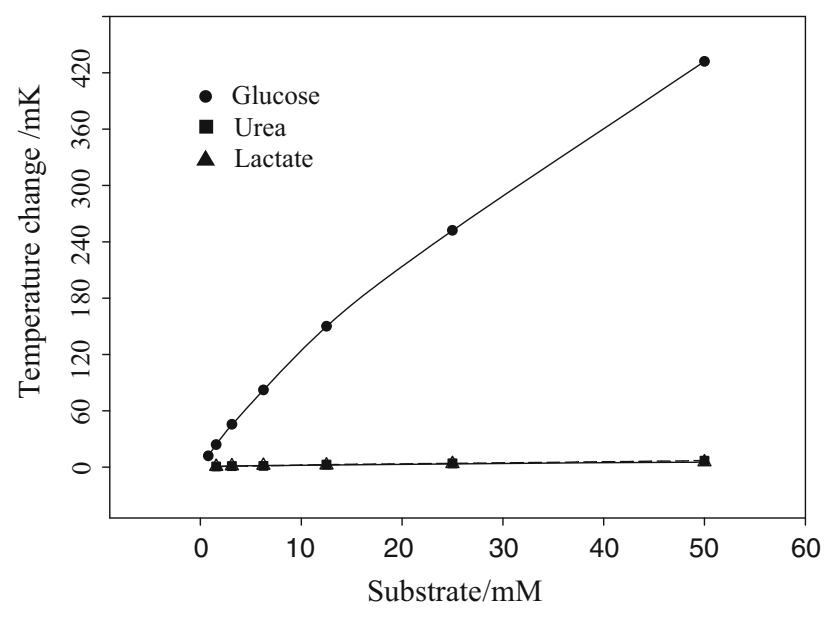

Fig. 7 Comparison of the responses using PQQGDH-ET for determination of glucose, urea, and lactate, respectively

\section{Conclusions}

Diabetes is a chronic disease that has devastating human and societal consequences. Its prevalence is expected to double over the coming 20 years. The development of efficient glucose-monitoring systems is therefore an essential part of clinical treatment. Here, a novel strategy was evaluated by combining pyrroloquinoline quinone glucose dehydrogenase (PQQGDH) with calorimetric detection. This resulted in a broad glucose measurement range and insensitivity of the thermal biosensor to electrochemical/optical interferences of common blood components.

As expected, the PQQGDH-ET showed an oxygen-independent characteristic and a linear range of glucose sensing from $0.009 \mathrm{mM}$ to over $100 \mathrm{mM}$. Additionally, reliable and long-life performance over 4 months was achieved. The results obtained provide a feasibility platform for the PQQGDH-based thermal biosensor in clinical monitoring of intensive care or surgical operation patients.

Acknowledgements The authors thank Professor Ulla Wollenberger at University of Potsdam for providing apo-glucose dehydrogenase (EC 1.1.99.17). Swedish Research Council (VR 2009-5405) and the Swedish Fund for Strategic Research (RBP14-0055) are acknowledged for financial support of this work.

Open Access This article is distributed under the terms of the Creative Commons Attribution 4.0 International License (http://creative commons.org/licenses/by/4.0/), which permits unrestricted use, distribution, and reproduction in any medium, provided you give appropriate credit to the original author(s) and the source, provide a link to the Creative Commons license, and indicate if changes were made.

\section{References}

1. Ceban I, Blajovan R, Vlase G, Albu P, Koppandi O, Vlase T. Thermoanalytical measurements conducted on repaglinide to estimate the kinetic triplet followed by compatibility studies between the antidiabetic agent and various excipients. J Therm Anal Calorim. 2016;126:195-204.

2. Mosbach K, Danielsson B. An enzyme thermistor. Biochim Biophys Acta Enzym. 1974;364:140-5.

3. Danielsson B, Mosbach K. Enzyme thermistors. Methods Enzymol. 1988;137:181-97.

4. Xie B, Harborn U, Mecklenburg M, Danielsson B. Urea and lactate determined in $1-\mu \mathrm{L}$ whole blood with a miniaturized thermal biosensor. Clin Chem. 1994;40:2282-7.

5. Carlsson T, Adamson U, Lins P-E, Danielsson B. Use of an enzyme thermistor for semi-continuous blood glucose measurements. Clin Chim Acta. 1996;251:187-200.

6. Chen Q, Andersson A, Mecklenburg M, Xie B. Fast determination of antibiotics in whole blood. Clin Microbiol Infect. 2013;19:869-74.

7. Andersson A, Chen Q, Groop L, Bulow L, Xie B. Continuous and simultaneous determination of venous blood metabolites. Talanta. 2017;171:270-4.

8. Mandenius CF, Bulow L, Danielsson B, Mosbach K. Monitoring and control of enzymic sucrose hydrolysis using on-line biosensors. Appl Microbiol Biotechnol. 1985;21:135-42.

9. Birnbaum S, Bulow L, Hardy K, Danielsson B, Mosbach K. Automated thermometric enzyme-immunoassay of human proinsulin produced by Escherichia coli. Anal Biochem. 1986;158:12-9.

10. Lammers F, Scheper T. On-line monitoring of enzyme-catalyzed biotransformations with biosensors. Enzym Microbial Technol. 1997;20:432-6.

11. Pirvutoiu S, Surugiu I, Dey ES, Ciucu A, Magearu V, Danielsson B. Flow injection analysis of mercury (II) based on enzyme inhibition and thermometric detection. Analyst. 2001;126:1612-6.

12. Qie Z, Bai J, Xie B, Yuan L, Song N, Peng Y, Fan X, Zhou H, Chen F, Li S, Ning B, Gao Z. Sensitive detection of atrazine in tap water using TELISA. Analyst. 2015;140:5220-6.

13. Zhou Y, Liu Z, Yao N, Chen Y, Xie B. A novel biosensor based on an enzyme thermistor for sensitive measurement of chemical oxygen demand. Sensors. 2015;15:20501-10.

14. Rank M, Danielsson B. Implementation of a thermal biosensor in a process environment: on-line monitoring of penicillin $\mathrm{V}$ in production-scale fermentations. Biosens Bioelectron. 1992;7:631-5.

15. Rank M, Gram J, Nielsen KS, Danielsson B. On-line monitoring of ethanol, acetaldehyde and glycerol during industrial fermentations with Saccharomyces cerevisiae. Appl Microbiol Biotechnol. 1995;42:813-7.

16. Mishra GK, Mishra RK, Bhand S. Flow injection analysis biosensor for urea analysis in adulterated milk using enzyme thermistor. Biosens Bioelectron. 2010;26:1560-4.

17. Chen Y, Andersson A, Mecklenburg M, Xie B, Zhou Y. Dualsignal analysis eliminates requirement for milk sample pretreatment. Biosens Bioelectron. 2011;29:115-8.

18. Zhou S, Zhao Y, Mecklenburg M, Yang D, Xie B. A novel thermometric biosensor for fast surveillance of beta-lactamase activity in milk. Biosens Bioelectron. 2013;49:99-104.

19. Xie B, Danielsson B, Norberg P, Winquist F, Lundström I. Development of a thermal micro-biosensor fabricated on a silicon chip. Sens Actuators B. 1992;6:127-30.

20. Xie B, Danielsson B, Winquist F. Miniaturized thermal biosensors. Sens Actuators B. 1993;15-16:443-7. 
21. Xie B, Mecklenburg M, Öhman O, Winquist F, Danielsson B. Microbiosensor based on an integrated thermopile. Anal Chim Acta. 1994;209:165-70.

22. Xie B, Mecklenburg M, Danielsson B, Öhman O, Norlin P, Winquist F. Development of an integrated thermal biosensor for the simultaneous determination of multiple analytes. Analyst. 1995;120:155-60.

23. Oubrie A. Structure and mechanism of soluble glucose dehydrogenase and other PQQ-dependent enzymes. Biochim Biophys Acta. 2003;1647:143-51.

24. Olsthoorn AJ, Duine JA. On the mechanism and specificity of soluble, quinoprotein glucose dehydrogenase in the oxidation of aldose sugars. Biochem. 1998;37:13854-61.

25. Si Z, Zhu J, Wang W, Huang L, Wei P, Cai J, Xu Z. Novel and efficient screening of PQQ high-yielding strains and subsequent cultivation optimization. Appl Microbiol Biotechnol. 2016;100:10321-30.

26. Babanova S, Matanovic I, Chavez MS, Atanassov P. Role of quinones in electron transfer of PQQ-glucose dehydrogenase anodes-mediation or orientation effect. J Am Chem Soc. 2015;137:7754-62.

27. Sarauli D, Peters K, Xu C, Schulz B, Fattakhova-Rohlfing D, Lisdat F. 3D-electrode architectures for enhanced direct bioelectrocatalysis of pyrroloquinoline quinone-dependent glucose dehydrogenase. ACS Appl Mater Interface. 2014;6:17887-93.

28. Gladisch J, Sarauli D, Schäfer D, Dietzel B, Schulz B, Lisdat F. Towards a novel bioelectrocatalytic platform based on "wiring" of pyrroloquinoline quinone-dependent glucose dehydrogenase with an electrospun conductive polymeric fiber architecture. Sci Rep. 2016;6:19858-67.

29. Slaughter G, Kulkarni T. Highly selective and sensitive selfpowered glucose sensor based on capacitor circuit. Sci Rep. 2017;7:1471-9.
30. Dogan K, Kayalp D, Ceylan G, Azak A, Senes M, Duranay M, Yucel D. Falsely elevated glucose concentrations in peritoneal dialysis patients using icodextrin. J Clin Lab Anal. 2016;30:506-9.

31. Lamas-Ardisana PJ, Martínez-Paredes G, Añorga L, Grande HJ. Glucose biosensor based on disposable electrochemical paperbased transducers fully fabricated by screen-printing. Biosens Bioelectron. 2018;109:8-12.

32. Hatada M, Loew N, Inose-Takahashi Y, Okuda-Shimazaki J, Tsugawa W, Mulchandani A, Sode K. Development of a glucose sensor employing quick and easy modification method with mediator for altering electron acceptor preference. Bioelectrochem. 2018;121:185-90.

33. Hoenes J, Unkrig V. Method for the colorimetric determination of an analyte with a PQQ-dependent dehydrogenase. Patent. 1994; CA 2120453 A1.

34. Enzyme Danielsson B, Devices Thermistor. In: Blum LJ, Coulet PR, editors. Biosensor principles and applications. New York: Marcel Dekker Inc; 1991. p. 83-105.

35. Qubrie A, Rozeboom HJ, Kalk KH, Olsthoorn AJJ, Duine JA, Dijkstra BW. Structure and mechanism of soluble quinoprotein glucose dehydrogenase. EMBO J. 1999;18:5187-94.

36. Dokter P, van Wielink JE, van Kleef MA, Duine JA. Cytochrome $b_{562}$ from Acinetobacter calcoaceticus L.M.D. 79.41. Its characteristics and role as electron acceptor for quinoprotein glucose dehydrogenase. Biochem J. 1988;254:131-8.

37. Loughran MG, Hall JM, Turner APF. Development of a pyrroloquinoline quinone (PQQ) mediated glucose oxidase enzyme electrode for detection of glucose in fruit juice. Electroanal. 1996;8:870-5. 